\title{
DESEO DE DECIR
}

\author{
Ixiar Rozas Elizalde \\ Mondragon Unibertsitatea \\ Azala Espazioa
}

Resumen

Una de las maneras de contar hoy pasa por rematerializar el lenguaje, por poner en primer plano la materialidad, el ritmo y la sonoridad de las palabras. Cuando lo que más explota el capitalismo postfordista es nuestra capacidad comunicativa y lingüística, y en medio de la textualización virtual de la vida, qué decir, entonces, cómo decir, con qué palabras y qué cuerpos. Trabajar desde la práctica artística con el universo de lo lingüístico, no significa necesariamente generar narratividad. Escribir sobre las maneras de contar hoy, no significa discursivizar. Es lo que sucede en algunas piezas artísticas que traspasan lo textual (la vista) para desplazarse a lo sonoro (la escucha) y a una oralidad que pone el cuerpo a la escucha.

\section{Palabras clave: LENGUAJE; SONORIDAD; ORALIDAD; ESCUCHA; MATE- RIALIDAD}

\section{DESIRE TO SAY}

\section{Abstract}

One of the ways to tell today is to rematerialize the language, to put in the foreground the materiality, the rhythm and the sonority of the words. When what most exploits post-fordist capitalism is our communicative and linguistic capacity, and in the middle of the virtual textualization of life, what to say, then, how to say, with what words and what bodies. Working from artistic practice with the linguistic universe does not necessarily mean generating narrativity. Writing about the ways of telling today does not mean discursivizing. This is what happens in some artistic pieces that go beyond the textual (the view) to move to the sound (listening) and to an orality that puts the body listening.

Keywords: LANGUAGE; SONORITY; ORALITY; LISTENING; MATERIALITY

\footnotetext{
Rozas Elizalde, Ixiar. "Deseo de decir". AusArt 6 (1): 31-41. D0I: 10.1387 /ausart.19431
}

\section{AUSART}


Fue un deseo de decir.

Decir, por ejemplo, que la arena es incontable.

O querer que playa rime con toalla. $Y$ silencio con sutura.

Era agosto de 2016. María Salgado y yo recibimos una invitación a crear sendas piezas sonoras para la megafonía de la playa de la Concha de Donostia. Una invitación del Observatorio de la escucha ${ }^{1}$ que buscaba intervenir en uno de los iconos de la ciudad, el escenario de la playa de la Concha, y en parte de su atrezzo, su megafonía, conocida por emitir mensajes muy codificados en aras de la claridad y efectividad comunicativa. Un dispositivo de amplificación que difunde, como la mayoría de las megafonías funcionales, avisos, alertas metereológicas e informaciones prácticas diversas. Existía una prohibición estricta de no comunicar nada más a través de esa megafonía pero,tras conseguir los permisos necesarios, logramos emitir una pieza sonora cada día, a las 20:20 h, durante todo el mes de agosto. Justo antes del cierre de las "cabinas colectivas" y después del último mensaje de la cruz roja anunciando su fin de jornada. Esa temporalidad, con ese horario, significaba que las piezas al ser amplificadas podían ser escuchadas por muchísimas personas.

Consciente de que en la megafonía, dispositivo con flujo comunicativo estandarizado y semánticamente limitado, las palabras nunca son algo en sí mismas sino que son funcionales, María Salgado creó un Catálogo de pre-viva voz para cualquier posible situación, que jugaba, precisamente, con la forma de los mensajes habituales. La poeta madrileña buscaba "ampliar el número de posibilidades verbales mediante la grabación de numerosos trozos de lengua que de tan laterales o raras puedan no servir para nada, de modo que la combinación multiplicada de posibilidades verbales dé en algo que imposiblemente sea como una orden o como una información plausibles. No servir para mucho ni estandarizar, ni constreñir, ni funcionalizar" (Salgado 2016).

Por mi parte, me preguntaba, ¿qué y cómo decir en una megafonía susceptible de ser escuchada por cientos de personas, en el "marco incomparable" de la playa de La Concha? Opté por crear un paisaje sonoro, una intervención en la que el ritmo, la repetición y la sonoridad de las palabras fracturaban el flujo lingüístico, buscando generar cierto extrañamiento. Al final todo sucede a la vez estaba divivida en dos piezas a las que cada día añadí 30 segundos de escucha. La primera, emitida en euskera, era un material basado en repeticiones loop en el que cada frase sumaba ligeras diferencias. La segunda era una 
suerte de inventario enumerativo del paisaje frontal de la playa que hacía referencia al silencio, a la hemorragia del discurso y a cuestiones como la tortura, por mi vinculación literal al paisaje de mi infancia, el marco incomparable del País Vasco y su conflicto político de décadas.

Al alejarse de la función meramente semántica del lenguaje, y por tanto, de su verdad, este proyecto subvertía, interrrumpía y fracturaba de manera poética los códigos comunicativos habituales. Si bien las piezas partían del texto escrito, fueron pensadas y trabajadas para ser dichas en voz alta con mecanismos de repetición, saltos, ecos, loops, relieve y capas textuales.

Modos de decir con la lengua y con la voz que generaban una textura a la que llamaré paratexto.

Eran meros deseos de.

\section{DECIR TEXTUALIZADO}

Decir cuando resulta que es precisamente nuestra capacidad lingüística y comunicativa, nuestro deseo de decir lo que es fetichizado. Cuando resulta que lo que más produce y explota el capitalismo postfordista son, precisamente, las maneras de experimentar con la subjetividad.

Cada día recibimos el impacto de miles y miles de palabras e imágenes por internet. Estamos rodeadas de texto y de imágenes que son, a su vez, texto y en nuestras pantallas virtuales generamos continuamente texto. Walter Benjamin habló de Schriftum, lo escritural, cuando a principios del siglo XX en su Berlín natal empezaban a proliferar los anuncios luminosos y la prensa escrita. Ante el cambio drástico que sufrió el paisaje urbano de su ciudad y la proliferación de lo escrito, de la palabra, tanto en prensa como en los anuncios, Benjamin dijo: "Lo escritural gana en anchura lo que pierde en profundidad" (citado en Cuenca 2015).

El trabajo postfordista contemporáneo es en su mayoría de tipo comunicativo y lingüístico, tiene lugar permanentemente ante la mirada del/a otro/a (Virno2003). Si los trabajos contemporáneos se configuran, entonces, principalmente como campos discursivos, performativos, creativos y de intercomu- 
nicación, los artistas son hoy trabajadores ideales para el capitalismo contemporáneo. De hecho, "se supone que el artista es la base sobre la cual debería modelarse la fetichización contemporánea de la creatividad y la subjetividad creativa y flexible neoliberal" (Kunst2015, 159).

Como es sabido, el debate sobre la proximidad del trabajo artístico y el capitalista comenzó a finales de los años noventa bajo la influencia de Luc Boltanski y Eve Chiapello. El nuevo espíritu del capitalismo insiste en las semejanzas entre la subjetividad artística y la subjetividad del capitalismo contemporáneo. La explotación de las potencialidades, las capacidades comunicativas y la flexibilidad -disponibilidad permanente- del sujeto trabajador, la introducción del virtuosismo en el lugar de trabajo, la disolución de la diferencia entre trabajo y tiempo libre, el aumento de la capacidad performativa del trabajador contemporáneo. Tampoco es ninguna coincidencia que el estilo de vida artístico y la explotación de la vida como proceso creativo sin fin subyazca a la especulación sobre el valor futuro del arte. La contradicción salta a la vista: los procedimientos para acercar el arte y la vida -en el siglo XX, su objetivo principal era abrir el potencial emancipatorio del arte y desplazar el centro de atención al proceso de creación desconectándolo de la materialidad del objeto artístico- están ahora en el núcleo de la creación capitalista de valor (Kunst2015, 155).

En este contexto de explotación comunicativa y virtuosismo lingüístico, en medio de la textualización virtual de la vida, ¿qué decir, cómo decir, cómo contar el sentido de nuestra experiencia, con qué palabras, con qué textualidades, con qué materialidad, con qué cuerpo?

\section{DECIR EN VOZ ALTA. PARATEXTO}

El paratexto trabaja con la lengua como materia prima sin relacionarse necesariamente con una creación de significado o de sentido, o con las formas de producción de texto tradicionales pertenecientes a la página escrita.

Digo paratexto para hablar sobre un marco de prácticas artísticas que trabajan con la performatividad del decir y de la voz en el espacio, parten de un texto -aunque no necesariamente-, y elaboran una oralidad que se aleja de la página escrita, que se escucha en lugar de ser leída, y no es logocéntrica. 
Podríamos decir que es fonocéntrica, porque se basa en una oralidad que en algunos casos trabaja la voz de manera específica. Sin embargo, no se trata del fonocentrismo metafísico de los griegos (Cavarero2003) y tampoco de la oralidad primaria de la que nos habla Walter Ong en su libro sobre la poralidad entre la oralidad y el conocimiento de la escritura² ${ }^{2}$.

Se trata de un texto abierto o escribible ${ }^{3}$, que permite múltiples interpretaciones para ir más allá, ya que la lectora no recibe el texto de manera escrita a través de la vista. He desarrollado la idea de la oralidad del texto escrito en Pulsión textual haciendo referencia a las maneras en que la voz atraviesa un texto alejándose de la noción habitual de voz narrativa y también del granulado de la voz barthesiano. Una voz física y material, performativa, única y relacional, siguiendo la filosofía de la voz de Adriana Cavarero, que también se desplaza de la página escrita (Rozas 2015).

En plena textualización virtual de la vida podriamos hablar también de texto expandido, como se viene haciendo en el ámbito de los estudios culturales y teatrales ${ }^{4}$. Sin embargo,opto por el concepto de paratexto porque traspasa lo escrito o visual para trasladarnos a lo sonoro. A partir de la conceptualización "campo expandido" llevada a cabo por Rosalind Krauss ${ }^{5} e n$ el ámbito de la escultura, y siguiendo la interpretación post-estructuralista del texto realizada por Roland Barthes, se desarrolla una nueva manera de comprender la escritura que sirve para explicar algunas obras del arte conceptual desarrolladas durante la década de los años setenta. Las obras de Marcel Broodthaers, Laurie Anderson, Hannah Weiner y Vito Acconci, por citar las más conocidas,son algunos ejemplos de este desplazamiento de la escritura desde la página impresa hacia otros formatos como la performace o la instalación artística. También en el ámbito de la coreografía se habla de coreografía expandida a la hora de afirmar que la coreografía debe ser redefinida para tener en cuenta a todos aquellos -incluidos artistas- que utilizan estrategias coreográficas sin relacionarlas necesariamente con la danza.

El término de texto expandido nos serviría, entonces, para aludir al desplazamiento de lo lingüístico de la página escrita hacia otros formatos como el audiovisual, lo escénico, la performance, la instalación, las redes sociales y etc. También para hablar de intervenciones, situaciones, entornos construidos, espacios escénicos, performances, coreografías, trabajos audiovisuales, vídeo, cine, instalación en los que la tradicional aproximación al texto -leído, presentado, dicho- se reorganiza, se repiensa, se experimenta. Sin embargo, con el texto expandido seguimos en el territorio de lo escrito. 
Frente a la idea de texto expandido, el concepto de paratexto nos sitúa en un contexto de producción de piezas artísticas que traspasan lo textual -la vista- para desplazarse a lo sonoro -la escucha-; a una escritura desplazada, en este caso, hacia una oralidad que pone el cuerpo a la escucha. Al decir aquí paratexto me alejo de su definición habitual -conjunto de enunciados que acompañan el texto principal de una obra, es decir, título, subtítulos y etc. - y sigo el camino que Esperanza Collado ha abierto en el ámbito del cine experimental. A la hora de teorizar sobre el cine expandido, Collado ha optado por el concepto de paracínema para referirse a nuevas producciones de cine experimental y su desmaterialización. El paracínema demuestra que las obras de arte ya no existen como objetos que siguen la producción tradicional y se desmaterializan incluso de la pantalla (Collado2012).

En el marco de las prácticas artísticas sonoras, ya desmaterializada del libro y muy alejada de la producción tradicional o la escritura literaria con una búsqueda de sentido, el paratexto reimte, entonces, a la cultura de lo paralingüístico y lo sonoro (LaBelle2014).

Piezas que parten o pasan por lo escrito, que es significado, signo, ritmo o, dicho de otra manera, grafía, gesto y sonido, sin relacionarse necesariamente con una creación de significado, para llevarnos a una oralidad material y física, que nos permite cuestionarnos sobre su propia ontología y re-experienciar la experiencia.

Dicen desde y a través de sus bocas,gargantas, lenguas, glotis, respiración, toses, titubeos, obstrucciones y salivaciones.

\section{DECIR CON LA BOCA}

Boca, cavidad, carne, suntuosidad.

Boca, humedad de salida, entrada.

Boca, antesala de la voz. 
Boca, órgano fundamental a la hora de ponernos en relación con y pensar la voz en términos de relacionalidad y unicidad. Observa el artista y escritor noruego Brandon LaBelle que en la teoría cultural la boca ha sido ensombrecida por la cuestión de la voz. Se pregunta si la boca ha ido desapareciendo en los discursos sobre la voz, perdiéndose entre las nociones de vocalidad y el reino del imperativo lingüístico $-y$ textual- (LaBelle 2014, 8). Yo misma ahora escribo sobre la oralidad que se desplaza del texto y lo hago a través de un escrito, pero una escritura que tiene en cuenta, o al menos lo intenta, los ritmos y sonoridades, y trato de bocalizar y masticarlas palabras que escribo. LaBelle sostiene que incluso trabajos que buscan profundizar nuestra relación con la voz como material fónico, que desafían la lógica dominante de lo semántico, también priorizan la voz, la dan por descontado, en lugar de pensarla como algo que surge de la garganta, de las profundidades el cuerpo además de del sistema lingüístico. En lugar de pensar la voz como un lugar de tensión oral. Pero no sólo no se piensa la voz como lugar de tensión oral, añadiría ahora a la afirmación de LaBelle, sino que la voz ha sido ninguneada y ensombrecida por la palabra y su verdad semántica. La falta de tensión oral de la voz es consecuencia de este ensombrecimiento histórico y usurpación de carnalidad (Rozas 2014, 208-9).

La boca es uno de los puntos centrales de entrada y salida del cuerpo, y ese espacio interior exteriorizado a través de la voz. Nuestra voz pone en común interiores e interioridades. El habla suena hacia fuera desde nuestra interioridad para ser enviado hacia otra persona.

Hace unos años entrevisté a la performer eslovena Irena Tomazin, quien lleva años investigando la voz desde su práctica artística y trabaja con lo vocal como materia prima. Tomazin me explicó que llegó a la voz a través de la danza y la fisicalidad. En sus piezas Caprice Relapse o As a raindrop falling into the mouth of silence, la artista busca una voz que corporeiza el cuerpo y un cuerpo que corporeiza la voz. En trabajos más recientes como su serie Faces of voices, Tomazin se centra únicamente en los sonidos que emergen de la boca. Ahí la voz está entrelazada en la boca y la boca en la voz, tanto que teorizar sobre la performatividad de lo hablado es confrontar la lengua, los dientes, los labios y la garganta; es sentir la boca como carne, con una sonoridad en cada sílaba, así como un orificio con textura que marca la voz de manera específica, "no únicamente en términos de acento o dialecto, sino también por la profundidad de la expresión, tan central para el cuerpo" (LaBeIle 2014,1). 
Si pensamos la voz en relación a la boca y las sonoridades del cuerpo, la voz como un evento primario que circula entre los cuerpos para agitar sus sonoridades, silencios, ritmos y entonaciones. Si pensamos la voz como una fuerza elemental que opera para animar al/a otro/a, para acercarlo. Si pensamos la voz de esta manera, nos alejamos de la noción de lenguaje como poder tan extendida desde el postestructuralismo y nos situamos en el decir como deseo. En el deseo de decir.

Otro cuerpo que escucha y devuelve la escucha de lo recibido. Pura deriva de materialidad fónica y sonora en la que voz cuerpo que escucha y dice y toca al decir con todo su cuerpo desdibuja los límites entre los cuerpos a la escucha.

Toda voz activa una escucha. La voz es precisamente un sonido lleno de cuerpo, un cuerpo bajo presión y a la búsqueda de algo, de otro cuerpo. Alguien habla, me habla, y lo que escucho no es la voz, sino el cuerpo, el sujeto del cuerpo que habla desde toda su unicidad. Al decir unicidad no me refiero a algo único e incompartible, tampoco a esencias inamovibles del sujeto, sino a lo que nos hace ser lo que somos, a nuestra particularidad, hecha para ser compartida con los demás.

\section{DECIR COMO REGISTRO VERBAL DEL SONIDO}

Al escuchar la voz de Gertrude Stein una imagina paisajes ${ }^{6}$.

Cosas que rompen distancias.

Cosas que son otras cosas y son siempre otras cosas y son.

El decir de Stein se desplaza entre el significado y el ritmo. Del campo semántico comprensible a la extrañeza sonora de sus palabras plásticas. La autora americana utiliza el lenguaje como registro verbal de la sensación sonora, de los signos. Escribe, por ejemplo, seguido del título Naranja: "Nueva clase ajajá no nueva que va a rodillar de añeja tajada de añojo ni poco tampoco" (Stein [1914] 2011, 104). 
Lenguaje como interrupción del orden del discurso, de la relación entre las palabras y las cosas. Cuando escribió Tender Buttons ${ }^{7}$ en 1914, Stein se posicionó radicalmente contra la imposición del orden de la representación $Y$ nuestra manera de leer se altera muta, se transforma en otra cosa que son otras cosas y son siempre otras cosas. No podemos dejar de leer. Leemos viendo las palabras en la página, tocándolas, alterándolas, invirtiéndolas, estrujándolas.

Con Stein, al leer escuchamos y tocamos. Al escuchar, nos inclinamos.

La audición es una posibilidad para la vulnerabilidad, del cuerpo y de los sentidos, así como de proporcionar una porosidad mayor entre los lazos del conocimiento y de lo social.

Escuchar es también situarse en la proximidad de la distancia.

Para escuchar, para pensar, para sentir el sentir se hace precisa cierta distancia.

Escuchar es adoptar una posición de no conocimiento. Es situarse a la espera del evento, a la voz y al sonido que puedan venir; es una preparación para un reconocimiento común. Escuchar como un espacio de encuentro hecho de agitaciones primarias, las que envuelven y desenvuelven los sentidos, para animar los lugares intermedios. La escucha nos permite pensar y habitar cuestiones de percepción, corporeización, espacialidad, territorialidad, materialidad.

O estar inmersa en el lenguaje sin necesidad de dominarlo o poseeerlo o sin ser poseído por él —como sucedía a movimientos de las vanguardias modernas como el surrealismo, el letrismo o el dadaísmo-.

Lo único que cambia de una época a otra depende de la manera en la que hacemos, decimos, miramos y escuchamos las cosas ${ }^{8}$.

Prácticas artísticas, performativas, sonoras, poéticas. $Y$ así rematerializan la lengua. $Y$ así reexperienciamos la experiencia. 


\section{Referencias}

Bernstein, Charles. 1992. A poetics. Cambridge: Harvard University

Boltanski, Luc \& Eve Chiapello. 2007. The new spirit of Capitalism.London: Verso

Cavarero, Adriana. 2003. A piùvoci. Filosofiadell'espressionevocale. Milano: Feltrinelli

Collado Sánchez, Esperanza. 2012. Paracinema. La desmaterialización del cine en las prácticas artísticas. Madrid: Trama

Cuenca Amigo, Jaime. 2015. "Lo escritural y la imagen: En torno a la actualidad del autor como productor". Eremuak 2

Donaldson, Peter S. 1997. Digital archive as expanded text: Shakespeare and electronic textuality. Oxford: Oxford Univesity

Hejinian, Lyn. 2000. The language of inquiry. Berkley CA: University of California

Kunst, Bojana. 2015. "Las dimensiones afectivas del trabajo artístico: La paradoja de la visibilidad". Traducción, Isabel de Naverán. En Ejercicios de ocupación: Afectos, vida y trabajo, Quim Pujol \& Ixiar Rozas, eds. Barcelona: Polígrafa

- . 2015. Artist at work: Proximity of art and Capitalism.London: Zero Books

LaBelle, Brandon. 2014. Lexicon of the mouth: Poetics and politics of voice and the oral imaginary. London: Bloomsbury

Ong, Walter J. (1982) 2016. Oralidad y escritura: Tecnologías de la palabra. Traducción de Angélica Scherp. México DF: Fondo de Cultura Económica

Rozas Elizalde, Ixiar. 2014. Beltzuria. Iruñea: Pamiela

— . 2015. "Pulsión textual". En Ejercicios de ocupación: Afectos, vida y trabajo, Quim Pujol\& Ixiar Rozas, eds. Barcelona: Polígrafa

Salgado, María [María Fernández Salgado]. 2016. "Catálogo de pre-viva voz para cualquier posible situación". Texto de la intervención artística dentro del programa del Observatorio de la escucha Donostia-San Sebastián- DSS2016, 1-13 agosto, playa de La Kontxa

— . 2016. Hacía un ruido: Frases para un film político. Madrid: Contrabando

Seminario Euraca. 2017- . Revista L/E/N/G/U/A/J/E/o. https://seminarioeuraca.wordpress.com/ revista-lenguajeo/

Stein, Gertrude. (1914) 2011. Botones blandos. Ed. de Esteban Pujals Gesalí. Madrid: Abadá

Virno, Paolo. 2002. Esercizidiesodo: Linguaggio e azione politica. Verona: Ombre Corte

— . 2003. Quando il verbo si fa carne: Linguaggio e natura humana. Milano: Bollati Boringhieri

Voegelins, Salomé. 2010. Listening to noise and silence. London: Continuum Books

\section{Notas}

${ }^{1}$ Observatorio de la escucha fue un proyecto comisariado por los artistas sonoros e investigadores Mikel R. Nieto y José Luis Espejo en el marco de la Capitalidad Cultural de Europa Donostia/San Sebastián 2016. Fue posterior la publicación del CD 20.20,que recoge la grabación del sonido directo de las piezas emitidas. Quiero agradecer a Mikel, José Luis 
y María por acompañarme en un proyecto que me ha dado tanto que pensar y seguir trabajando.

${ }^{2}$ Si bien defienden el fonocentrismo y la oralidad, con su modelo de narración de pirámide de Freitag y la epopeya griega, la filosofía griega continúa trabajando la narración por escrito (Ong [1982] 2016, 218-20).

${ }^{3}$ Roland Barthes distinguía, como es sábido, entre textos legibles y escribibles. Los primeros seguían una explicación lógica y lineal, sin permitir al lector o lectora intervenir en él. Los textos escribibles son, sin embargo, los que permiten al lector o lectora hacer múltiples interpretaciones (Ong [1982] 2016, 248).

${ }^{4}$ Ver, por ejemplo, Peter S. Donaldson:Digital Archive as Expanded Text: Shakespeare and Electronic Textuality, Oxford: Oxford Univesity Press, 1997.

${ }^{5}$ En 1978 Rosalind Krauss puso de manifiesto la ampliación del ámbito de la escultura hacia nuevas prácticas artísticas que trabajan con medios híbridos como el arte del paisaje, el vídeo arte y el arte procesual. Y con ello activó el concepto de campo expandido que luego se ha ido desplazando a otros campos de conocimiento y lenguajes artísticos.

${ }^{6} \mathrm{http}: / /$ writing.upenn.edu/pennsound/x/Stein.php

${ }^{7}$ Sigo aquí la excepcional edición y traducción que Esteban Pujals hizo al castellano, Botones blandos.

${ }^{8}$ Del ensayo titulado "Three lives" de Lyn Hejinian, donde retoma lo que escribió Gertrude Stein en "Composition as explanation" (Hejinian 2000, 286-7). 